\title{
Lapping flat surfaces with forced dosing of abrasive suspension
}

\author{
Maciej Gniot ${ }^{1, *}$, Adam Barylski ${ }^{2}$ \\ ${ }^{1}$ UTP University of Science and Technology, Faculty of Mechanical Engineering \\ ${ }^{2}$ Gdańsk University of Technology, Faculty of Engineering
}

\begin{abstract}
The issues concerning the finishing of flat ceramic seals are presented in the paper. The treatment requirements demanded from the elements of that type cause, that necessary is application of grinding-in in the technological process. Such a precise abrasive treatment of flat surfaces of that type, requires the use of an appropriate suspended matter or abrasive paste. Many factors connected with metal grinding-in shield, components of abrasive suspended matter and the treatment's technological conditions, have an impact on the treatment's result. The manner and intensity of the suspended matter's proportioning in the grinding-in are, are also of decisive nature. A standard, free manner of proportioning, in a continuous manner most often dipping or dropping, results in big losses of abrasive material. A part of abrasive micro-grains is quickly removed from the operating grinding-in shield by the rotating rings leading separators with treated elements and does not take part at all in machine cutting. It considerably increases the tool costs and has an unfavourable impact on the natural environment. Implementation of the forced abrasive suspended matter's proportioning at the time of the machine grinding-in, considerably reduces these losses.
\end{abstract}

\section{Innovative proportioning system}

The developed innovative proportioning system makes it possible to control appropriately the volume and frequency of the abrasive suspended matter's applying on the specific place on the tool's operating surface. It also makes it possible to prepare the suspended matter of optimum viscosity. The constructed test stand for one-side grinding-in of flat surfaces, is based on the construction of the lapping machine Abralap 380 (Fig. 1).

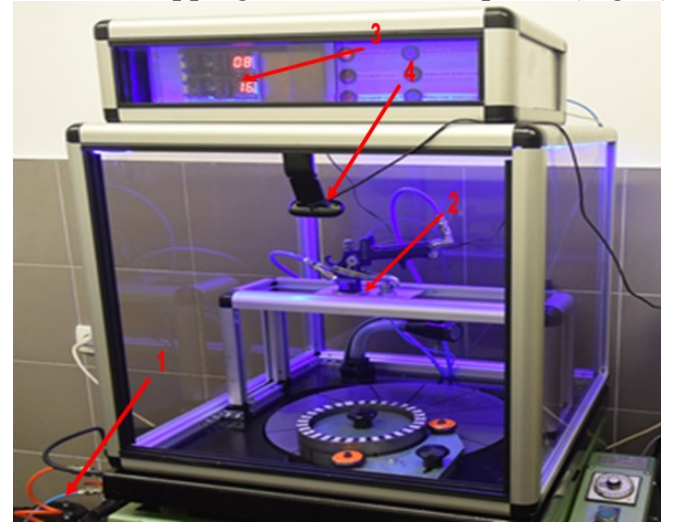

Fig.1. Forced system of proportioning and applying the abrasive suspended matter: 1- system of constant mixing, 2- system of the suspended matter's application, 3- control system, 4- camera registering the process.

\footnotetext{
*Corresponding author: maciej.gniot@utp.edu.pl
} 
The system of proportioning and applying of the abrasive suspended matter's applying, is divided into two systems. The first of them answers for preparation and supplying of the abrasive suspended matter (Fig. 2 and 3).

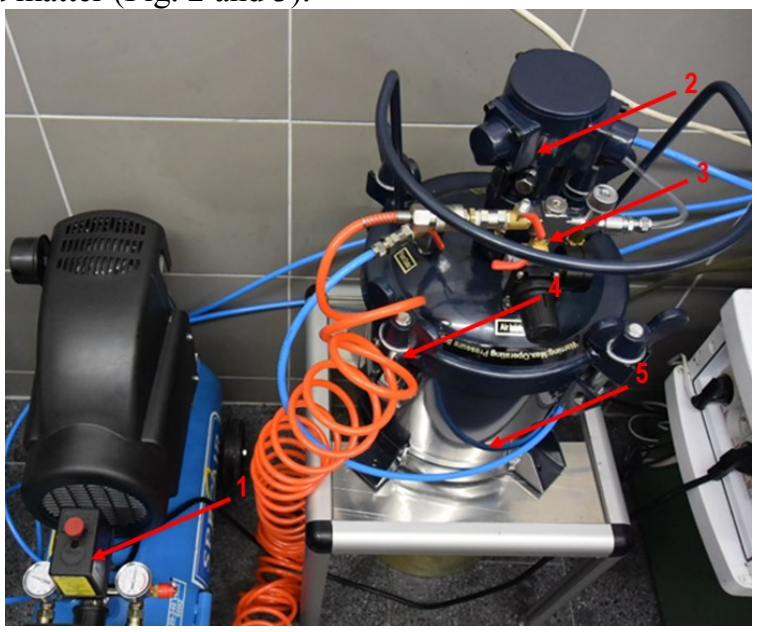

Fig. 2, System of the abrasive suspended matter's preparation: 1- compressor, 2- power transmission of the mixer's rotor, 3- pressure regulating device regulator inside the tank, 4- the tank's cover, 4suspended matter's tank, 5- bowl of the tank.

The system of the abrasive suspended matter's applying (Fig. 4), makes it possible to apply a layer of the assumed thickness (expressed per one rotation of the lapping tool). The system also has the option of controlling the volume of the applied spot of abrasive suspended matter, its shape and placement of the shield (Fig. 5). The process of proportioning and applying, is controlled via the electronic system.

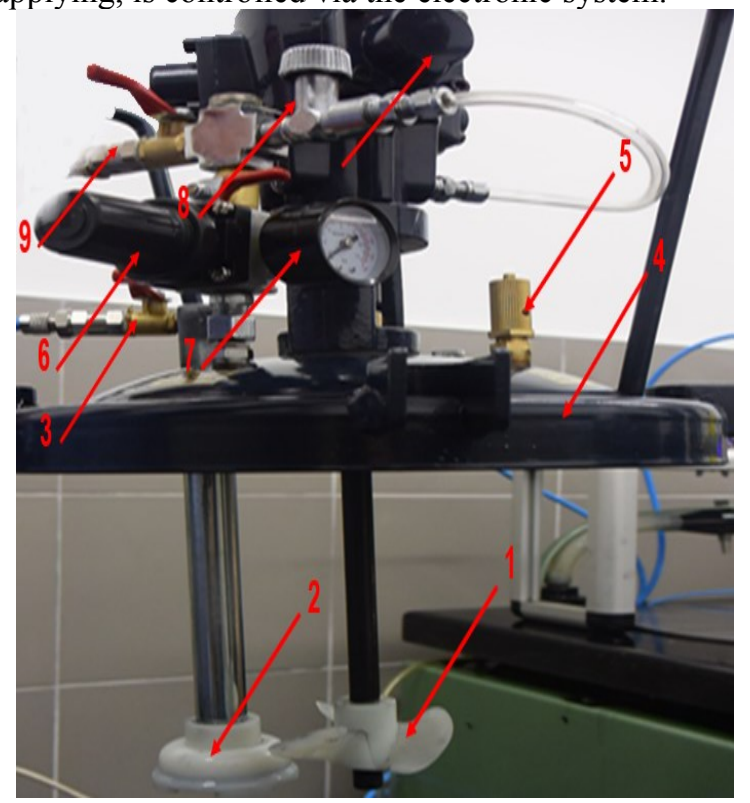

Fig. 3. System of continuous mixing of the abrasive suspended matter: 1- mixer's screw, 2- dragon, 3feeding of the applying apparatus with the abrasive suspended matter, 4- tank's cover, 5- safety valve, 6- air pressure regulator, 7- pressure gauge, 8- mixer's rotational speed regulator, 9compressed air terminal. 
As it may be observed, the size and shape of the stain depend on the pre-set settings. It may also be found, that the system makes it possible to proportion the volume of a single suspended matter's dose, what translates into the possibility of planning the total consumption of the abrasive suspended matter at the moment of planning the elements' grinding-in process, taking into consideration their properties. Maintaining of a certain, assumed thickness of the applied layer on the lapping tool's shield during the course of the whole grinding-in process, is also possible [1-4].

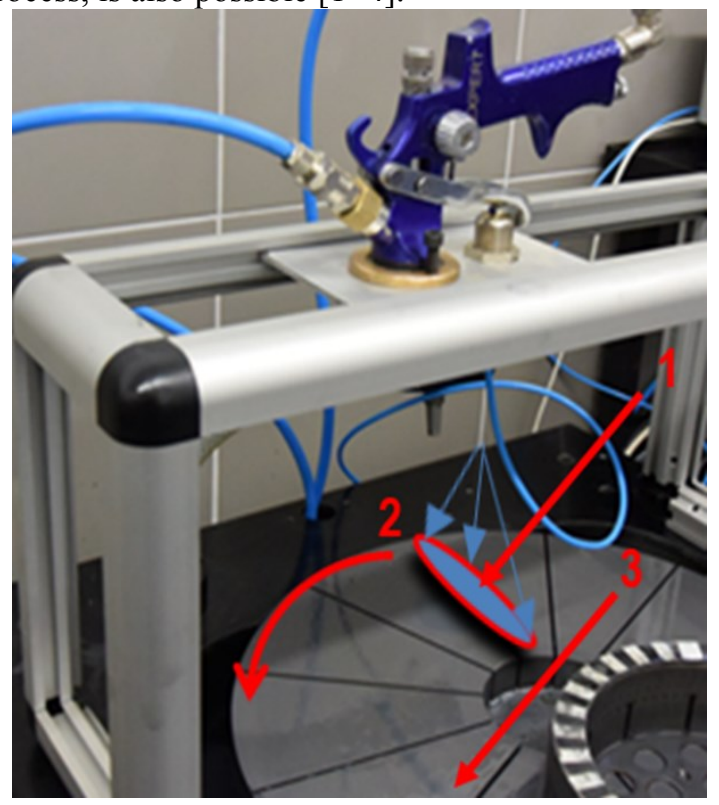

Fig. 4. System applying the abrasive suspended matter on the lapping tool: 1- shape of the stain made of the abrasive suspended matter, 2- direction of the lapping tool's rotation, 3-applied layer of the suspended matter.

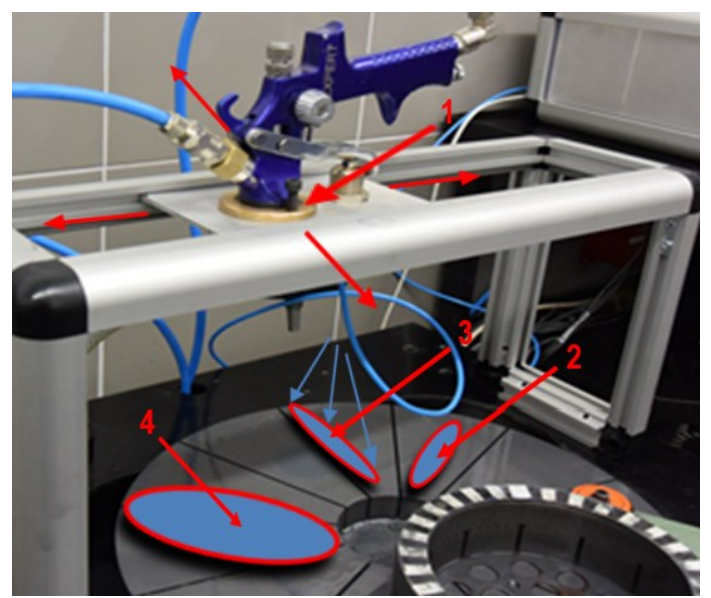

Fig. 5 Possible location of the applied abrasive suspended matter's layer (1- system of the applied layer location's change on the lapping tool's shields, 2- possible stain's location on the shield, 3possible stain's location on the shield of a specified size, 4- possible stain's location on the shield with hanging area). 


\section{Selection criteria of the research programme}

Setting about to own studies, requires assessment of technical possibilities concerning making measurements of the selected elements, and ensuring an appropriate test stand. Identification, within the scope of the volumes of tests possible to be realized in order to conduct a correct process on their basis, is the necessary element of preparations for basic tests' conducting. Also, an estimate time of tests' realization is to be assessed and the financial costs connected with such an undertaking is to be determined. For that purpose, based on the criteria discussed in the previous section, that is efficiency and informativity of individual research programmes $[5,7,11,13]$, there shall be conducted the process of identification. In order to make comparison possible, the number of the tested factors and the necessary number of the tests is to be determined, just as to make it possible to obtain the sought, highly reliable information $[6,9,14]$. In Fig. 6 , there is presented the diagram of proceeding at the time of the individual solutions' usability valuation, the selected research programmes.

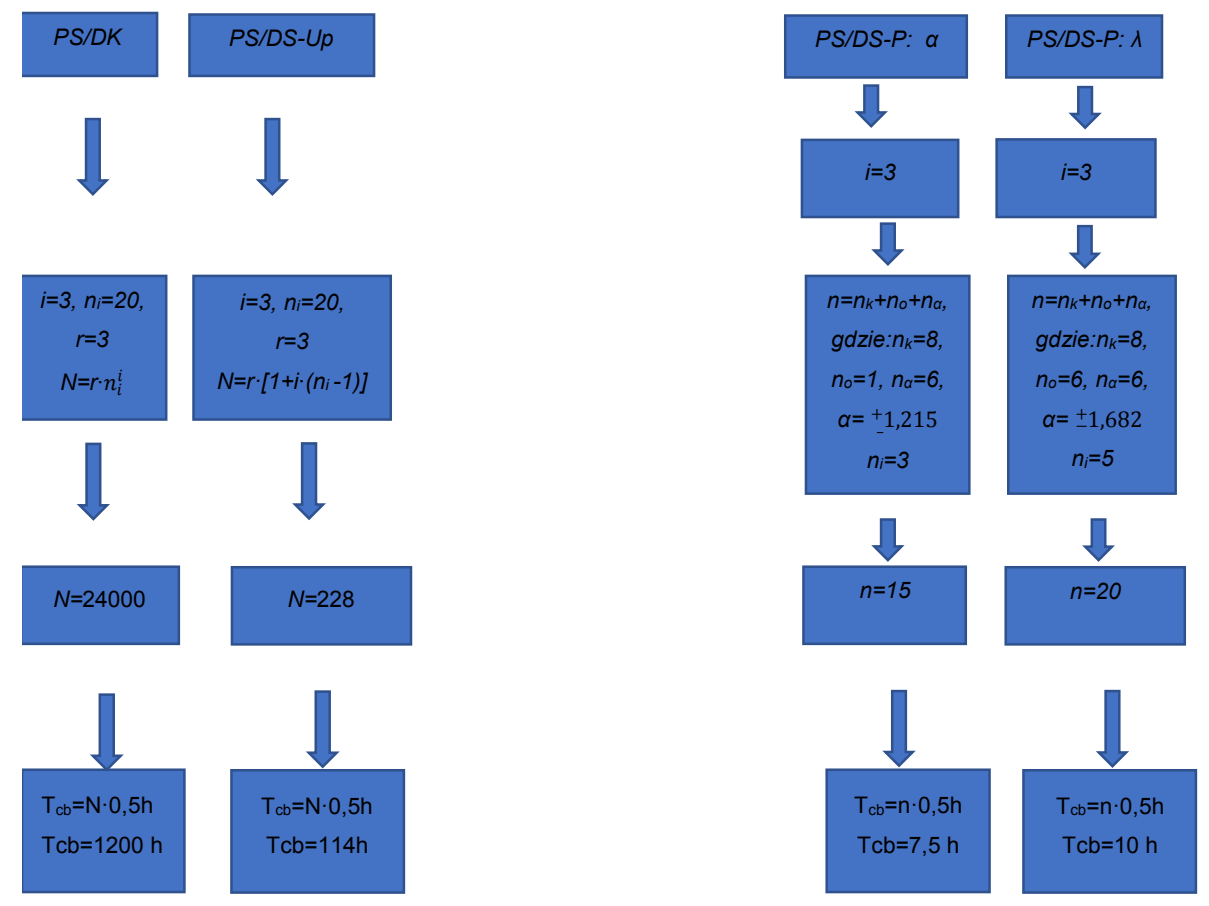

Fig. 6. Comparative diagram of research programmes.

The tested factors have been determined theoretically, based on the analysis of the applied abrasive suspended matter's proportioning manners.

Analysing the potential possibility of the PS/DK programme's use for own studies it was found, that the programme in its assumption uses all the possible configurations of tested factors (that is, each one with each one), what of course translates into the following possibilities. Assuming that $\mathrm{i}=3$ tested factors, number of tests $\mathrm{ni}=20$, and $\mathrm{r}=3$ three repetitions, there was received the total number of tests that should be conducted $\mathrm{N}=24000$. It is a very big number, assuming that the time of one single test $\mathrm{t}=0,5 \mathrm{~h}$, what gives us the realization time on the level of Tcb $=1200 \mathrm{~h}$. Assessing the usability of the PS/DK programme it was found, that the programme's informativity strongly depends on the number of the tested factors and their arrangement in the intervals $\left[\mathrm{x}_{\max }, \mathrm{x}_{\min }\right]$, what influences a long tests' time. 
Also the PS/DS.-Up programme has been analysed from the point of its possible use for the tests. This programme uses other possibilities, namely it is based on selecting the tested factors $\mathrm{X}$ and determining their central values. The central values determined in such a manner do not change at the time of subsequent tests concerning the impact of a single $\mathrm{X}$ factor. In order to make it possible to determine the central value, for the first there should be conducted the preliminary analysis of the tested object. The PS/DS-Up programme has the character of the procedure unequivocally determined prior to the tests' commencement, following determination in the first place of the programme central values. Informativity of the PS/DS-Up programme is slightly limited as compared to the PS/DK programme, and to a considerable degree it depends on the arbitrary selection of the central values. The number of the required measurements in the PS/DS-Up programme amounts to $\mathrm{N}=228$ with the same assumptions for $\mathrm{i}=3, \mathrm{ni}=20, \mathrm{r}=3$. The total time of the tests at that programme's assumptions, has been assessed for Tcb $=114 \mathrm{~h}$.

Programmes PS/DS-P: $\alpha$ and the programme PS/DS-P: $\lambda$ in their assumptions make use of the nonlinear model in the form of the second degree multinomial. The second-degree multinomial influences:

- limitation of the number of measurements,

- limits complications connected with statistical calculations and the recourse analysis.

The basic feature of the programmes PS/DS-P: $\alpha$ and PS/DS-P: $\lambda$ is implementation of special compositions (systems) of the tested factors' values ensuring the so-called orthogonality notion which concerns the PS/DS-P: $\alpha$ and the notion of rotatability connected with the programme PS/DS-P: $\lambda$. During analysis usability of the above programmes for the tests it was found, that while choosing the PS/DS-P: $\alpha$ programme, the tests shall be realized at four levels, and the total number $n$ of the systems for measurement's realization $n=15$, the time of the tests' realization with the use of that programme shall amount to Tcb $=7,5$ h. In the programme PS/DS-P: $\lambda$, the tests shall be realized at five levels, and the total number $\mathrm{n}$ of systems for the measurements' conducting $\mathrm{n}=20$, the time of the tests' realization with the use of that programme shall amount to $\mathrm{Tcb}=10 \mathrm{~h}$.

Finally, for conducting of the tests concerning grinding-in of flat ceramic elements with the forced proportioning of the abrasive suspended matter, there has been selected the programme PS/DS-P: $\lambda$ as its time consumption amounts to $\mathrm{Tcb}=10 \mathrm{~h}$, informativity is relatively high, and the model described in this programme shall be the second degree multinomial, what shall allow for graphic interpretation of the function's form $[5,6,9,14]$.

\section{Development of the experiment's results}

The developed and constructed abrasive suspended matter's proportioning system, makes it possible to conduct experimental studies of grinding in of flat ceramic sealing elements, with the use of the static, determined, selective, multi-factor, second degree quasi-rotatable PS/DS-P: $\lambda$, of spheroidal information's distribution plan of the tests [15]. Such a solution ensures stability of the recourse function's assessment in a given environment of the plan's central point. The programme is characterised with relatively high informativity and efficiency, what from the point of view of the tests' costs consumption, is an essential factor. The experiment, in case of three variable tested factors, requires conducting only $\mathrm{n}=$ 20 tests $[7,8,10,11,12]$.

As the variable factors, there have been selected the: percentage content of abrasive grains (weight share) $\mathrm{K}[\%]=\mathrm{x}_{2}$, dose of abrasive suspended matter applied on the shield for 20 minutes $\mathrm{Vs}[\mathrm{ml} / 20 \mathrm{~min}]=\mathrm{x}_{3}$, and viscosity of the mixture of the suspended matter's liquid components $\mathrm{Le}[\mathrm{mPa} \cdot \mathrm{s}]=\mathrm{x}_{4}$. The variability range of the tested factors has been determined based on the literature and preliminary studies. For the tests, as the abrasive grain, there has been used the silicon carbide $98 \mathrm{C} \mathrm{F400/17.} \mathrm{The} \mathrm{samples} \mathrm{made} \mathrm{of} \mathrm{Al}_{2} \mathrm{O}_{3}$ ceramics should be subject to grinding in. The values of the output factors $\mathrm{Y}$ in the 
experiments, are the variables of random character. Such a premise makes it possible to assume, that the occurring interferences $\mathrm{U}$ and the constant conditions $\mathrm{C}$, are the parameters seemingly fixed for determined tests' conditions. The function of the object has been determined in the multi-dimensional factor space, as the recourse equation: $[5,15,16]$.

$$
Y=F\left(x_{1}, x_{2}, x_{3}, \ldots, x_{k}\right)
$$

where:

$\mathrm{k}-$ is the number of the analysed variables.

Determined coefficients $B=\left[b 1, b 2, \ldots, b_{k}\right]$ concern the recourse equation:

$$
\begin{aligned}
Y= & b_{1} x_{1}+b_{2} x_{2}+b_{3} x_{3}+b_{4} x_{4}+b_{5} x_{2}^{2}+b_{6} x_{3}^{2}+b_{7} x_{4}^{2}+b_{8}\left(x_{2} * x_{3}\right)+ \\
& b_{9}\left(x_{2} * x_{4}\right)+b_{10}\left(x_{3}+x_{4}\right)
\end{aligned}
$$

where:

value of the output factor from the model, while the independent variables: $x_{1}=1, x_{2}=K$, $\mathrm{x}_{3}=\mathrm{Vs}, \mathrm{x}_{4}=$ Le.

The results of the conducted tests are to be subject to statistical analysis. Determining of the quadratic recourse equations describing the mass decrement Ubm and linear Ubl of the treated ceramic elements in the function of variable input data: $\mathrm{K}, \mathrm{Vs}$ and Le, is the basic task. Estimation of coefficients $b=\left[b_{1}, b_{2}, \ldots, b_{k}\right]$ of the recourse equation is the first step. If by $X$ we shall mark the experiment plan's matrix, and by $Y$ the column of the measurements results, then vector $B$ estimates with the use of the matrix formula in the form of

$$
B^{T}=\left(X^{T} X\right)^{-1} X^{T} Y
$$

where:

$X^{T}$ means the symbol of transaction's matrix $X$, and $\mathrm{X}^{-1}$ is the matrix reverse to the matrix $X$. Estimation of vector B is based on the least squares' method. The unbiased estimator of variance $\delta^{2}$ of the random component, is the statistics $\mathrm{s}^{2}$ determined with the formula:

$$
s^{2}=\frac{1}{n-k-1} \sum_{i=1}^{n}(y(i)-y t(i))^{2}
$$

where:

$y(i)$ is the $i$-th measurement point (i-th point of the experiment's plan), $y t(i)$ is the value of the recourse function in the $\mathrm{i}$-th point, $\mathrm{n}$ is the number of the plan's points, while $\mathrm{k}+1$ is the number of the recourse equations' coefficients. Formula (4) in the matrix form is the following:

$$
s^{2}=\left(Y^{T} Y-b^{T} X^{T} Y\right) /(n-k-1)
$$

The assumption on normality of the random component's distribution, makes it possible to determine the confidence intervals and making use of the appropriate statistical tests for coefficients bi $(i=1,2, \ldots, k)$ of the recourse equation. The multiple correlation coefficient $R$ is the parameter describing the quality of approximation with the empirical dependence equation P. The coefficient $R$ measures the dependence (correlation) level of the variable $Y$ on the independent variables $\mathrm{X}_{1}, \mathrm{X}_{2}, \ldots, \mathrm{X}_{\mathrm{n}}$. The square of the correlation coefficient is the coefficient of determination $\mathrm{R}^{2}$, where $y t(i)$ is the value of the function in the $\mathrm{i}$-th point of the experiment's plan, $y e(i)$ is the measured (empirical value) value, while $y s$ is the mean value calculated from all the experiment's results. So: 


$$
R^{2} \sum_{i=1}^{n} \frac{(y e(i)-y t(i))^{2}}{\sum_{i=1}^{n}(y s-y t(i))^{2}}
$$

The closer is the value of the correlation coefficient $R$, the higher is the degree of the variable explained by the recourse function. The value of $R$ close to zero, means the lack of dependence between the variable $Y$ and the set of variables $X_{1}, X_{2}, \ldots, X_{\mathrm{n}}$. In order to check, whether the correlation coefficient is significantly different than zero, the test of recourse's significance has been conducted. In this case, the zero test's hypothesis, has the form of:

$$
H_{0}: R=0
$$

The testing statistics for that hypothesis, is expressed with the formula:

$$
F=\frac{n-k-1}{k} \frac{R^{2}}{1-R^{2}}
$$

Random variable $\mathrm{F}$ has the F-Snedecor distribution, of the degrees of freedom $\mathrm{d}_{\mathrm{f} 1}=\mathrm{k}$ (numerator) and $\mathrm{d}_{\mathrm{f} 2}=\mathrm{n}-\mathrm{k}-1$ (denominator). The critical value $\mathrm{F}_{\alpha, \mathrm{df1} \text {,df2 }}$ for the pre-defined level of significance $\alpha$ is to be read from the statistical tables. At the time of the multi-factor recourse equation's construction, the tested variables which may have an impact on the value of the dependent variable $\mathrm{Y}$, should be taken into consideration. In order to check, which ones from the variables $X$ influence significantly the variable $Y$, it shall be necessary to conduct the test of significance for all the recourse coefficients of the defined equation. The zero hypothesis is then in the form:

$$
H_{0}: b_{i}=\beta_{i}
$$

The testing statistics is:

$$
t=\frac{b_{i}-\beta_{i}}{s_{b_{i}}}
$$

where:

$b_{i}$ - i-th recourse equation's coefficient (2),

$$
s_{b_{i}}=s \sqrt{d_{i i}}
$$

where, $\mathrm{s}$ is the standard deviation's equation (2), while $d_{i i}$ is the $\mathrm{i}$-th diagonal value of the matrix $\left(X^{\mathrm{T}} X\right)^{-1}$.

The statistics $t$ determined with the formula (10), while assuming genuineness of the $\mathrm{H}_{0}$ hypothesis, has the distribution of t-Student of n-k-1 freedom degrees. The critical area for that hypothesis is: $\left(-t_{n-k-1, \alpha}, t_{n-k, \alpha}\right)$. Such value $t_{n-k-1, \alpha}$ is determined from the table $t-S t u d e n t$ for $n-k-1$ levels of freedom and the level of significance $\alpha$.

Dispersion of the value of coefficient $b_{i}(i=1,2, \ldots, k)$ is described by the confidence interval:

$$
\left(b_{i}-t_{\propto s_{b_{i}}}, b_{i}+t_{\propto s_{b_{i}}}\right), \text { dla } \mathrm{i}=1,2, \ldots, \mathrm{k}
$$

where:

$$
P\left\{b_{i}-t_{\propto s_{b_{i}}}, b_{i}+t_{\propto s_{b_{i}}}\right\}=1-\propto
$$

while $1-\alpha$ is the level of confidence. 


\section{Summary}

The manner of applying the abrasive suspension matter has an essential impact on its consumption during the process's realization. It influences the treatment's effectiveness, the total cost of the process' realization, and the costs connected with utilization of the products' remaining following the completed process. Constructed forced proportioning and applying abrasive suspended matter's system together with the control system, makes it possible to implement limitations connected with the abrasive substance's consumption. In order to confirm that assumption, the research experiment is to be conducted obtaining the empirical results. The experiment should be conducted with the use of the research programme of the PS/DS-P: $\lambda$ programme. The obtained results are to be put through statistical analysis, and the object's function in the multi-dimensional factor space determined as the recourse equation. The obtained equations shall make it possible to create area diagrams of the impact of the selected factors, that is: $\mathrm{K}, \mathrm{Vs}$, Le on realization of the process of the elements' grinding-in made of $\mathrm{Al}_{2} \mathrm{O}_{3}$ ceramics.

\section{References}

1. A. Barylski, Docieranie powierzchni płaskich na docierarkach (Gdańsk, Wydawnictwo Politechniki Gdańskiej, 2013)

2. A. Barylski, M. Gniot, Wpływ zawiesiny ściernej dawkowanej w sposób wymuszony na wydajność docierania jednotarczowego elementów ceramicznych (Mechanik, 2018)

3. M. Gniot, A. Barylski, K. Migawa, System dawkowania zawiesiny ściernej w docieraniu powierzchni płaskich (Mechanik, 2017)

4. M. Gniot, A. Barylski, Hydrodynamiczne dawkowanie zawiesiny ściernej $w$ docieraniu jednotarczowym powierzchni płaskich (Mechanik, 2016)

5. Z. Polański, Metody optymalizacji w technologii maszyn (Warszawa, PWN, 1977)

6. Novye idei vplanirowanii eksperimenta, red. V. V. Nalimov, (Moskva, Nauka, 1969)

7. V. V. Nalimov, Teoria eksperymentu (Moskva, Nauka, 1971)

8. V. V. Nalimov, N. A. Czernowa, Statystyczne metody planowania doświadczeń eksperymentalnych (Warszawa, WNT, 1967)

9. J. Kiefer, Ann. Math. (Statistics, 1961)

10. H. Ahrens, Analiza wariancji (Warszawa, PWN, 1970)

11. B. Kacprzyński, Planowanie eksperymentów (Warszawa, WNT, 1974)

12. G. E. P. Box, K. B. Wilson, J. Royal Stat. Soc. (Ser. B, 13, 1951).

13. V. V. Federov, Teoria optymalnego eksperimenta. (Maskva, Nauka, 1971)

14. J. Kiefer, Proc.4-th Berkley Symp. (Match. Statistics and Prod. 1, 1961)

15. G. Box, J. Hunter, Multifactor experimental designs for exploring response surfaces (Ann. Match. Statist., 1957)

16. K. Mańczak, Technika planowania eksperymentu (Warszawa, WNT, 1976) 